\title{
Best Practice Grid Restoration with Hydropower Plants
}

\author{
S. Polster+, R. Schürhuber, H. Renner, L. Ruppert, R. Schmaranz, C. Rupp, \\ C. Tengg
}

\begin{abstract}
Events as the Italy blackout 2003 and the grid splitting 2006 cause to bring up grid restoration and black-start ability as an urgent topic for both grid and power plant operators. In this paper the requirements for participation in grid restoration and lessons learned from black-start and island tests in Carinthia 2017 are discussed. The evaluation of the tests shows, that the nozzle provision results in an increased frequency stability due to the fast control reaction.
\end{abstract}

\section{Introduction}

The share of volatile Renewable Energy Sources (RES), mainly wind and solar, in electrical energy generation has been rising dramatically during the last years. As one result the specifications of the electrical power system characterizing system stability have been changing, resulting in e. g. decreased system inertia available and transmission lines loading increased. Therefore, measures preventing and handling blackout scenarios have been moved into closer focus of the grid operators.

Grid operators developed coordinated grid restoration strategies in cooperation with research facilities to cope with this situation. These strategies are based on the evaluation of simulations and black-start respective island grid tests. Depending on the availability of units after blackout, grid restoration strategies contains top-down or bottom-up approaches. A top-down restoration is based on the availability of a stable supply in a neighbouring transmission system. The re-supply of the disturbed system is achieved by connecting to this stable supply. In case of a system wide blackout, the grid restoration starts with power plants with black-start-capability and small island grids according to the bottom-up strategies. The existing national strategies and restoration plans are European-wide harmonised by the ENTSO-E 'Network Code on Emergency and Restoration' which entered into force on 18.12.2017 [1]-[3]. The different strategies are discussed in more detail in [4].

The backbone of the Austrian bottom-up grid restoration strategy are pump storage power plants located in Salzburg and Carinthia. In this work general requirements for participation at grid restoration and possibilities for improving frequency stability in the early phase of a bottom-up grid restoration are discussed. Furthermore, the implementation of these improvements are evaluated based on the black-start and island grid tests in Carinthia in 2017.

\footnotetext{
+ Recipient of a DOC Fellowship of the Austrian Academy of Sciences at the Institute of Electrical Power Systems, TU Graz
} 


\section{Technical and organisational requirements}

In the event of grid restoration, power plants have to cope with more severe operational conditions than in normal operation. In the following, the main technical and operational requirements for power plants participating in a stable and secure grid restoration are described. The focus of this work is on power plant operation during system restoration, thus requirements of grid operators and control room applications, such as secure remote control of switches and the synchronisation of island grids, are not part of this paper.

Black-start capability: It must be possible to set a power plant into operation without external voltage supply to achieve black-start capability. Therefore, it is necessary to provide a secure supply for the control equipment and auxiliary facilities of the generator such as excitation, governor, valves or forced bearing lubrication. The supply can be provided either by self-excited support generators or diesel powered emergency generators. However, it must be mentioned, that the securing of a power plant into station service mode - as is usually the goal in the case of grid collapse does not account as black-start capability.

Control requirements: The generator unit must be able to meet the requirements on voltage and frequency deviation in island operation. Generally, the voltage control meets the dynamic requirements even in cases of larger load changes due to the small time constants (in the range of some seconds, [5]) of the excitation system and voltage controller. However, the high rate of change of frequency (ROCOF) in island grids during grid restauration due to the rather small rotational energy are a challenge for the frequency control.

Minimum load: Grid restoration requires a minimum of one generator operated from no-load to maximum load without limitations. Power control during low loading conditions must guaranty a precise and fast response to load changes. These requirements are generally met well by Pelton turbines. However, if a unit is operated at minimum load, this minimum load has to be provided reliably. From an organisational point of view, loads under direct control of one participant of the grid restoration (power plant operator or grid operator) are preferable. If the stabilising load is provided by a third party, it must be available at any given time and the remote connection must be secure in cases of a blackout for a predefined time, which should reasonably be around the regulated autonomy time of relevant switching stations of $24 \mathrm{~h} \mathrm{[1]}$.

Training: The grid restoration concepts have to practiced regularly by all participating parties under preferably realistic conditions. Dynamic grid simulators can be used to test individual tasks with several participants to locate and improve weak points in the grid restoration concept. Beside the simulation, black-start tests at the qualified power plants and grid areas are necessary to verify the requirements mentioned above. 


\section{Frequency stability increasing measures}

In early stages of grid restoration, frequency response during fast load changes is crucial for the stability of the island. In general, only a few generators are present at the island grid at this time and accordingly the rotational energy is rather small leading to a higher ROCOF compared to normal operation. Therefore, the maximal switchable load blocks are limited to not exceed the frequency limits.

This limitation causes an increased effort in the operations management due to more switching operations and bears the risk of a collapse of the island grid in case of a misjudgement of the switched load. In order to ensure a fast and reliable grid restoration, it is important to aim for an improvement in the frequency response, thus enabling larger load blocks to be connected during system restoration.

In principle, this can be achieved with the following options:

- Faster control

- Introducing more rotating energy leading to a decreased ROCOF

\subsection{Deflector control}

The control speed of the speed controller is given by the possible gradient of the hydraulic power of the turbine, which is primarily limited by the change rate of discharge, causing pressure variations in the penstock. In the following, the focus is laid on Pelton turbines as used in the investigated grid restoration test.

The hydraulic power of Pelton turbines is controlled by nozzle opening. Any change of the nozzle position causes an acceleration respectively deceleration of the water column and in the following a pressure wave, known as the water hammer, in the penstock. The resulting pressure values limit the achievable rates of change of discharge and nozzle position. Practically power gradients have to be limited to approximately 3 percent of the rated turbine power per second. However, a faster control reaction can be achieved for Pelton turbines by integrating the deflector in the power control. Deflectors are devices, which are able to turn into the jet between nozzle and turbine and redirect the flow or a part of it away from the turbine. The deflector has no repercussion on the penstock and is normally only used for fast load reduction and emergency shutdowns. It is possible to use the deflector for utilizing a sudden change of hydraulic turbine power by extending the power control of the turbine with a nozzle provision (NP).

During operation with active NP turbine power is directly controlled by the position of the deflector cutting of part of the water jet allowing it to react to increasing power demand as well. The nozzle position is tracking the deflector in order to guarantee the amount of the diverted water jet and therefore the power reserve for fast power increase. A welcome side effect of the NP is the reduction of the inverse turbine reaction. Inverse turbine reaction refers to the non-minimum phase property of the turbine process. This means that after opening a nozzle, the power drops temporary as the pressure difference on the nozzle declines temporary due to dynamic effects. 


\subsection{Additional Inertia}

In case of an imbalance between generation and load, the frequency gradient $\mathrm{d} f / \mathrm{d} t$ depends on the rotational energy of all rotating units connected to the grid. Additional rotation energy yields a smaller frequency gradient and allows a slower control time constant of the frequency control or larger load changes without violating frequency limits.

For stability studies in small scale islanded grids, the total rotational energy can be calculated by summing up the total inertia of all connected units. For a single unit, rotational energy $E_{\text {rot }}$ is calculated by:

$$
E_{\mathrm{rot}}=\frac{J}{2} \cdot\left(\frac{2 \pi n}{60}\right)^{2}
$$

For stability studies, usually the inertia constant $H$ is used as a measures of the rotational energy and thus for the reaction time of the system due to load changes:

$$
H=\frac{1}{2} \frac{J}{S_{\mathrm{r}}} \cdot\left(\frac{2 \pi n_{\mathrm{r}}}{60}\right)^{2}
$$

After a sudden change in the load a power difference $\Delta \mathrm{P}$ between the load and the mechanically supplied power of the generators will occur for the time before the frequency control is able to equalize the changed load power. The power balance of the system is obtained by withdrawing or supplying rotation energy to the system, whereby the change in time of the rotating energy corresponds to the power difference $\Delta P$. Due to the generally different rotational speeds of the machines, the consideration is simplified by introducing an equivalent moment of inertia Jeq based on a frequency of $50 \mathrm{~Hz}$. The equivalent moment of inertia is the sum of the machine inertia elements referenced to $50 \mathrm{~Hz}$.

$$
\Delta P(t)=\frac{\mathrm{d} E_{\mathrm{rot}}(t)}{\mathrm{d} t}=4 \cdot J_{e q} \cdot \pi^{2} \cdot f(t) \cdot \frac{\mathrm{d} f(t)}{\mathrm{d} t}
$$

The frequency gradient at time $t_{0}$ is calculated by rewriting equation (3):

$$
\left(\frac{\mathrm{d} f(t)}{\mathrm{d} t}\right)\left(t=t_{0}\right)=\frac{\Delta P\left(t_{0}\right)}{4 \cdot J_{e q} \cdot \pi^{2} \cdot f\left(t_{0}\right)}
$$




\section{Black-start and island grid test Carinthia 2017}

In the $110-\mathrm{kV}$ grid of Carinthia and southern parts of the $220 / 380-\mathrm{kV}$ grid of Austria, island grid and black-start trials have been regularly carried out since 2005 by the local distribution network operator KNG-Kärnten Netz GmbH (KNG), the transmission system operator Austrian Power Grid (APG) and the power plant operators KELAG and Verbund Hydro Power (VHP) in cooperation with Graz University of Technology. The focus of the island grid tests 2017 was set on the improvement of the frequency behaviour in load switching in the early stage of grid reconstruction, as well as the synchronization of local grid islands.

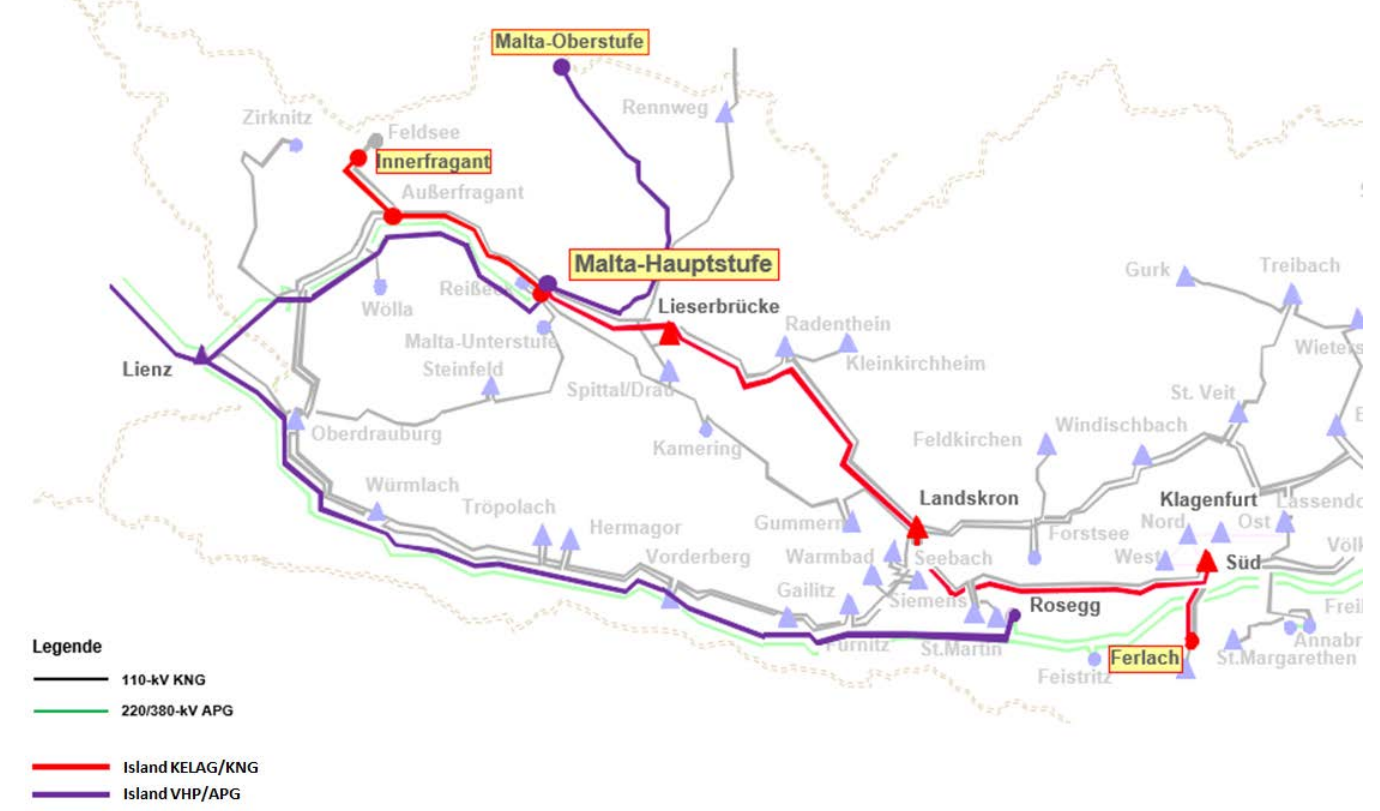

Fig. 1 participating power plants and test grid

The participating hydro plants KW Innerfragant and KW Malta Hauptstufe both have black-start capabilities, while the power plant Ferlach Maria Rain is synchronized to the already established island grid in later steps of the grid restoration concept and the fixed-speed pump located at KW Malta Oberstufe is used as load for the VHPIAPG island as well as in the synchronized island. The schematic grid structure is shown in Fig. 1. The bottom-up grid restoration which was utilized during the test and island synchronisation is out of scope of this paper. Therefore, test 1 to 3 are referred to tested measures to increase the frequency stability. The main technical data and the participation in the discussed tests is given Table 1. Generators O1, O2 and O3 as well as W4 and W5 are combined in terms for the task of frequency control and treated as single unit. 
$20^{\text {th }}$ International Seminar on Hydropower Plants, 14.-16.11.2018, Vienna/Austria

\begin{tabular}{|c|c|c|c|c|c|c|c|}
\hline $\begin{array}{c}\text { generator } \\
\text { unit }\end{array}$ & $\begin{array}{c}\text { rated } \\
\text { power } \\
\text { MVA }\end{array}$ & $\begin{array}{l}\text { speed } \\
\text { min-1 }\end{array}$ & $\begin{array}{c}\text { rot. } \\
\text { energy } \\
\text { MWs }\end{array}$ & $\begin{array}{l}\text { mode of } \\
\text { operation }\end{array}$ & $\begin{array}{l}\text { participating } \\
\text { in tests nr. }\end{array}$ & $\begin{array}{l}\text { location of } \\
\text { generator }\end{array}$ & turbine \\
\hline O $1-3^{*}$ & 108 & 750 & 280 & $\begin{array}{c}\text { Frequency } \\
\text { control }\end{array}$ & $1-3$ & KW Innerfragant & Pelton \\
\hline W 4-5* & 72 & 500 & 173 & $\begin{array}{l}\text { constant } \\
\text { power }\end{array}$ & $1-3$ & KW Innerfragant & Pelton \\
\hline Haselstein & 6 & 992 & 6 & pump load & + & KW Innerfragant & Pump turbine \\
\hline DMH 1 & 220 & 500 & 720 & no-load & 3 & $\begin{array}{l}\text { KW Malta } \\
\text { Hauptstufe }\end{array}$ & Pelton \\
\hline DMO 1 & 70 & 500 & 308 & pump load & $1-3$ & $\begin{array}{l}\text { KW Malta } \\
\text { Oberstufe }\end{array}$ & Pump turbine \\
\hline DMF 2 & 50 & 125 & 89 & $\begin{array}{l}\text { constant } \\
\text { power }\end{array}$ & $1-3$ & $\begin{array}{l}\text { KW Ferlach } \\
\text { Maria Rain }\end{array}$ & Kaplan \\
\hline
\end{tabular}

Table 1 participating generators, location and mode of operation, * $\mathrm{O} 3$ and W5 are equipped with NP, + Haselstein participated only as load before the island synchronisation

A comparison of performance in terms of frequency stability between NP and additional inertia is obtained by evaluation of the maximum frequency drop and the time passed till the frequency nadir is reached after a sudden load increase of $15 \mathrm{MW}$.

The rotational energy of the system for each separated test and the main measurement results are listed in Table 2 . The machine configuration of test 1 and 2 are unchanged, however, the NP of generator $\mathrm{O} 3$ is activated with a reserved power of $5 \mathrm{MW}$. The higher rotational energy in test 3 is achieved by synchronisation of an additional generator at no-load operation to the island grid. The share of the rotational energy of the additional generator amounts to $46 \%$ of the resulting overall rotational energy. The available control power is not changed due no-load operation.

\begin{tabular}{llcccc} 
& & Erot & $\mathrm{df} / \mathrm{dt}$ & $\Delta \mathrm{f}$ & $\mathrm{t}$ to $\mathrm{f}_{\text {min }}$ \\
& & $\mathrm{MWs}$ & $\mathrm{Hz} / \mathrm{s}$ & $\mathrm{Hz}$ & $\mathrm{s}$ \\
\hline Test 1 & Reference measurement & 850 & $-0,38$ & 1,4 & 6,6 \\
Test 2 & NP active & 850 & $-0,38$ & 0,67 & 5,6 \\
Test 3 & Additional rotation energy & 1570 & $-0,23$ & 1,14 & 9,4
\end{tabular}

Table 2 frequency gradients and time till frequency minimum 


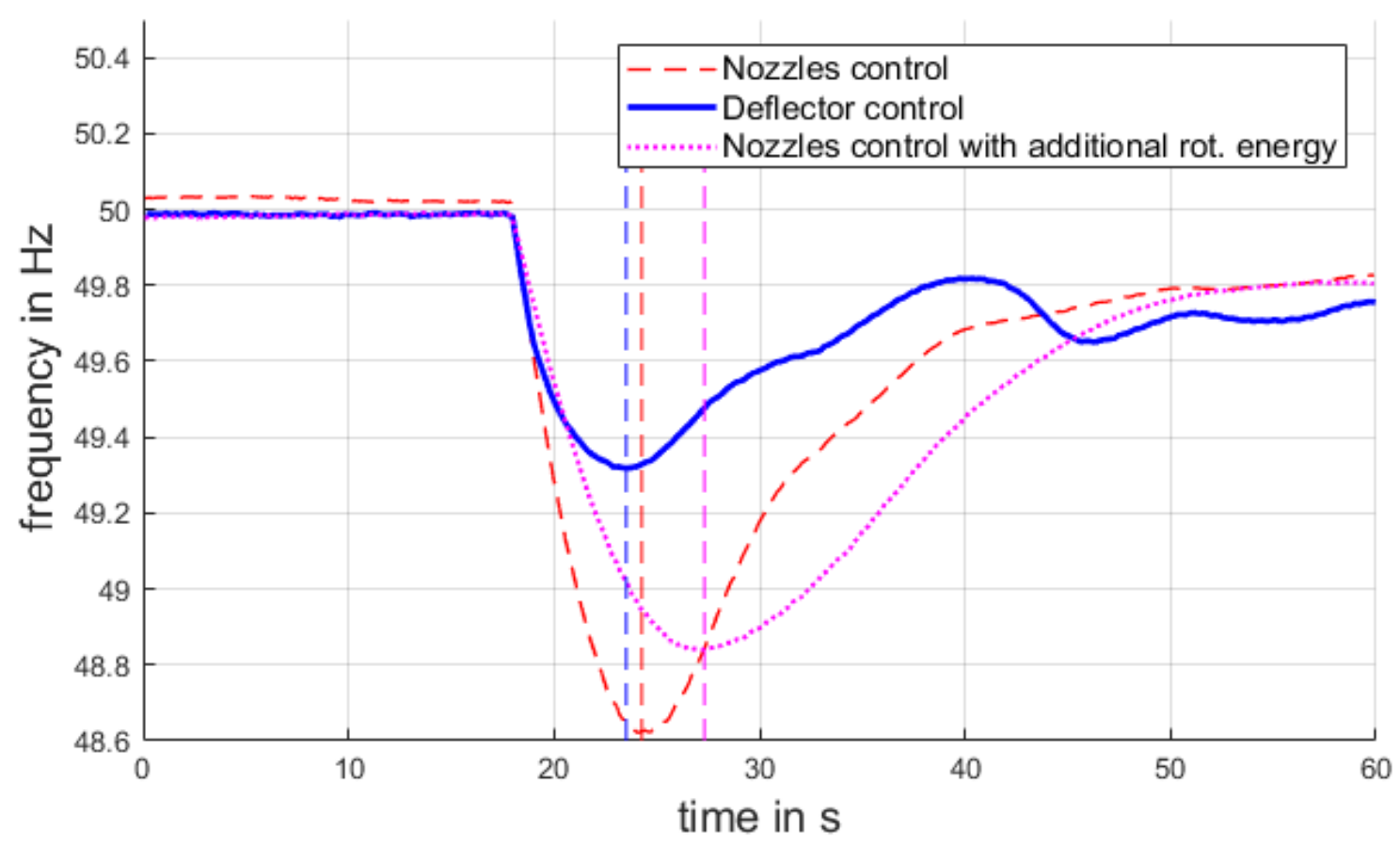

Fig. 2 Plot of frequency after sudden load increase of $15 \mathrm{MW}$ for the investigated unit and different control configurations

Both investigated measures improve the frequency stability in the investigated island grid, while the utilization of nozzle provision (NP) turns out to be more effective. However, improvement strongly depends on the power control of the frequency defining generators in the island grid. On one hand, additional rotating energy and therefore the reduction of the frequency gradient is more suitable for generator units with rather slow turbine controllers. On the other hand, a lower frequency gradient can lead to an unnecessary delay in the control response of fast turbine controllers, which can be seen by the increased time spend until frequency nadir is reached.

The effect of the NP and its activation are investigated further in a smaller island containing of the generator units 01-3 and W4-5 with Haselstein as single load. The load step of $5 \mathrm{MW}$ is achieved again by disconnection of the island with a power deficit of $5 \mathrm{MW}$ from the ETNSO-E grid.

Fig. 3 shows the change from common nozzle control to active NP. The power output is controlled by the deflector position after approximately $t=160 \mathrm{~s}$, whereat the deflector is moved into the water jet. The nozzle starts to open at the same time to provide the power reserve. After the oscillation is settled the generator has the same active power output as before. The small ripple is caused by mechanical vibrations of the deflector. 


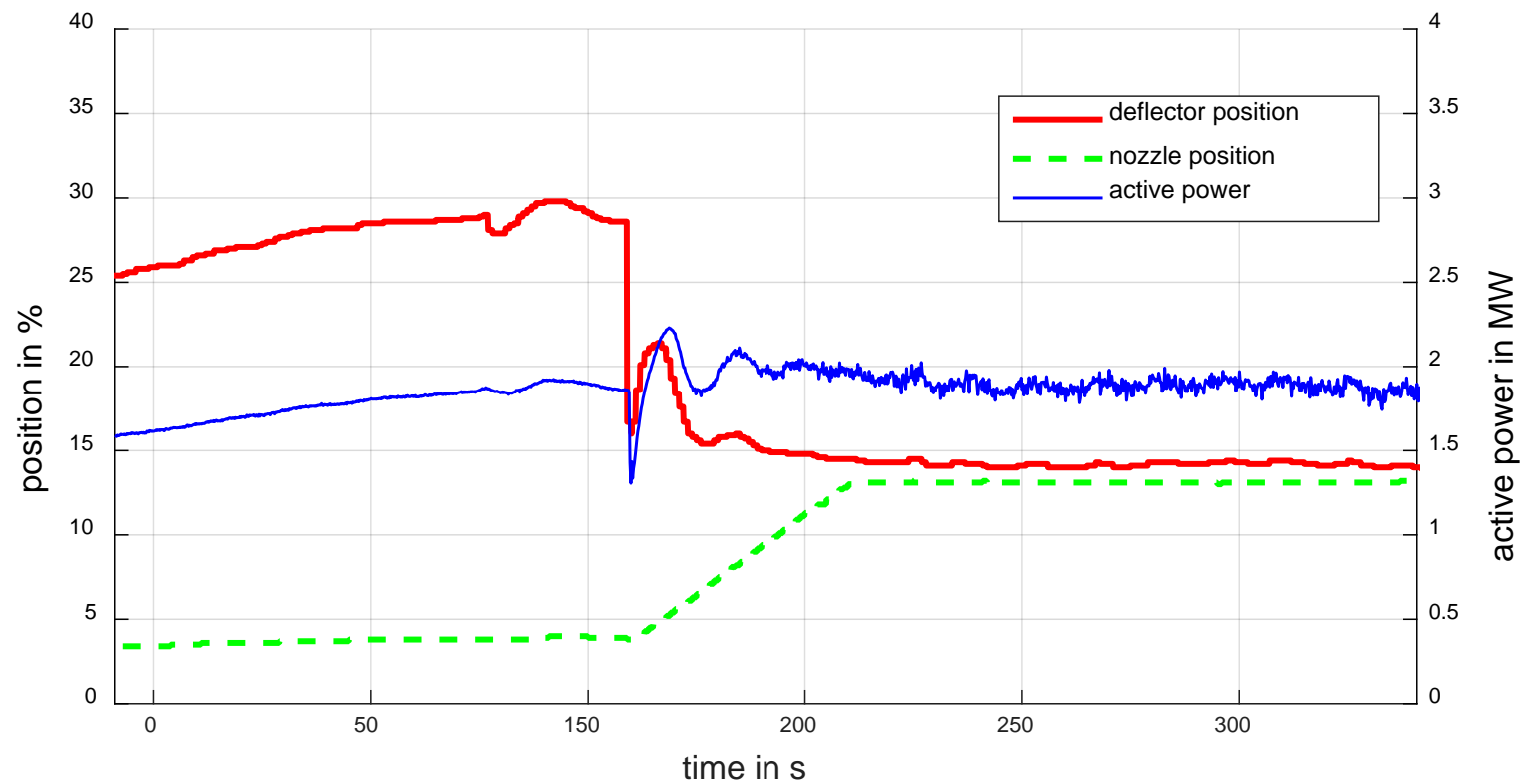

Fig. 3 active power, deflector and nozzle position during the activation of NP generator W5 in a weak loaded island with 5 parallel generators

Fig. 4 shows the frequency response and active power output with and without active NP. The frequency dip and time until frequency nadir is reached is significantly reduced and the inverse turbine reaction is nearly cancelled out.

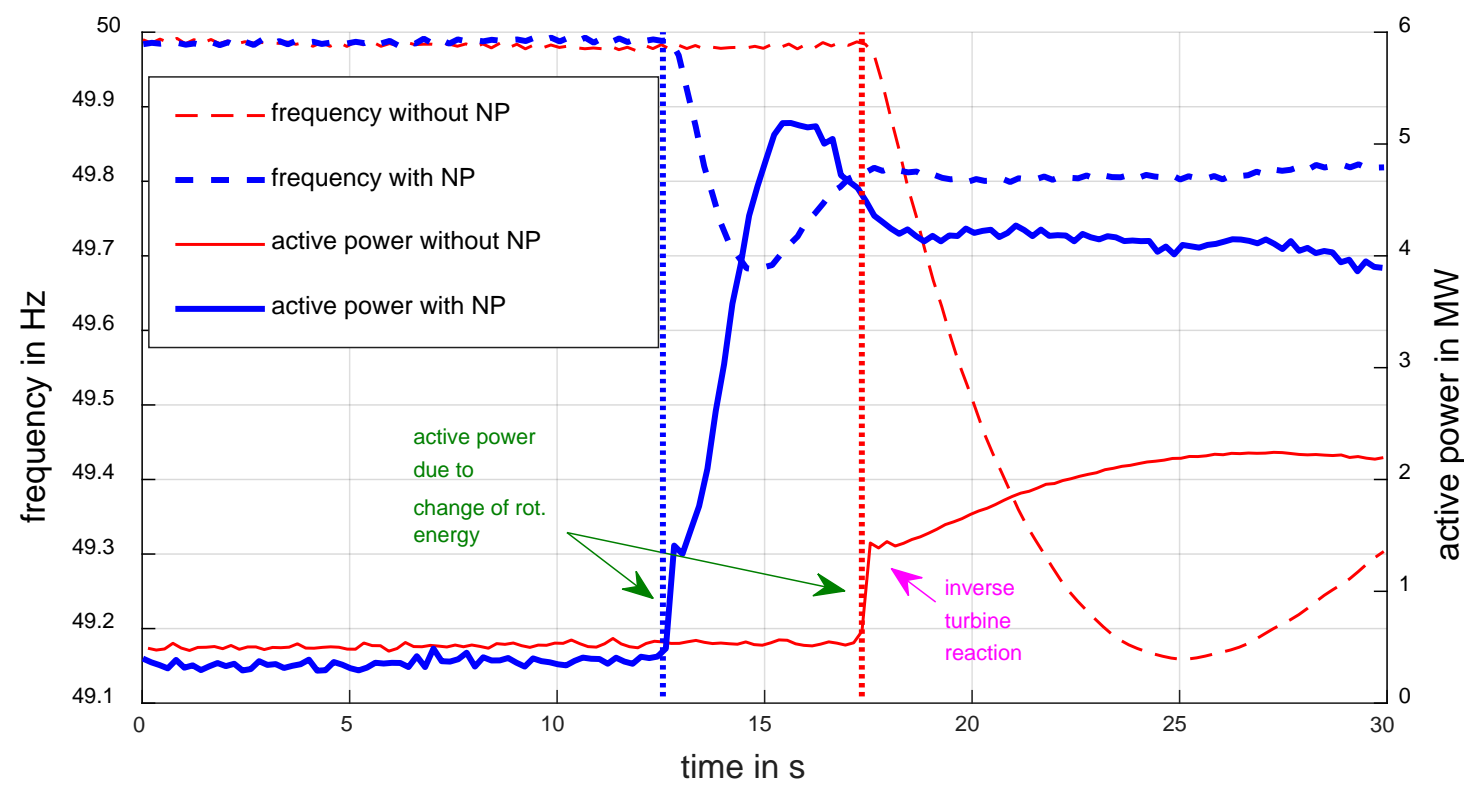

Fig. 4 frequency and active power output after a sudden $5 \mathrm{MW}$ load change of generator W5 with and without NP, dotted pointed line indicates time of load change 


\section{Conclusion}

The results from the black-start and island grid test show a significant improvement of the frequency stability of the island due to the use of NP. However, the timespan operating with active NP is restricted by the additional stress on the mechanical equipment of the generators.

The additional inertia leads to an improvement too. The improvement is lessened by a slower reaction of the fast power controllers of the participating generators. Therefore, additional inertia should be used preferable for island grids without fast reacting generator units.

A special load situation at the tests is caused by the operation behaviour of direct connected pump loads. The power-speed characteristic with a speed dependency to the power of three has a positive effect on frequency stability.

\section{References}

[1] ENTSO-E, "ENTSO-E Network Code on Emergency and Restoration," no. 714, 2015.

[2] Energie-Control Austria, "TOR - Teil B," no. September, pp. 2-7, 2013.

[3] Energie-Control Austria, "TOR - Teil C," no. September, pp. 2-7, 2013.

[4] Y. Guo et al., "Review on Network Restoration Strategies as a Part of the RestoreGrid4RES Project," in 15. Symposium Energieinnovation, 2018, vol. 1, pp. 1-8.

[5] J. Machowski, J. W. Bialek, and J. R. Bumby, Power System Dynamics: Stability and Control, 2nd ed. Re. Chichester: John Wiley \& Sons Ltd, 2008. 


\begin{abstract}
Authors
Stefan Polster

Graz University of Technology

Institute of Electrical Power Systems

Inffeldgasse 18/I, A-8010 Graz, AUSTRIA

Phone: +43 3168738061 FAX +43 316873 7553,

E-mail: stefan.polster@tugraz.at
\end{abstract}

Stefan Polster received the master degree in electrical engineering, in 2016, from Graz University of Technology, Austria, where he is currently working toward his Ph.D. degree. His research mainly deals with power system dynamics and load flow calculation. In 2017 he became a recipient of a DOC Fellowship of the Austrian Academy of Sciences at the Institute of Electrical Power Systems, Graz University of Technology.

\title{
Robert Schürhuber
}

Graz University of Technology

Institute of Electrical Power Systems

Inffeldgasse 18/I, A-8010 Graz, AUSTRIA

Phone: +43 3168737550 FAX +43 316873 7553,

E-mail: robert.schuerhuber@tugraz.at

Prof. Schürhuber received his Ph.D. in electrical engineering from Vienna University of Technology in 2003. From 2003 to 2009 he worked in various fields of electrical power engineering for Siemens Energy, with focus on instrumentation and control. In 2010 he joined Andritz Hydro, where he worked as a senior expert in the Electrical Power Engineering department, with focus on the electrical behaviour of large hydro installations. Since October 2017 he is head of the Institute of Electrical Power Systems at Graz University of Technology.

\section{Herwig Renner}

Graz University of Technology

Institute of Electrical Power Systems

Inffeldgasse 18/I, A-8010 Graz, AUSTRIA

Phone: +43 3168737557 FAX +43 316873 7553,

E-mail: herwig.renner@tugraz.at

Herwig Renner holds a position as associate professor at Graz University of Technology. His research is in the field of power system planning and operation with special focus on transmission system dynamics and industrial power quality. 
Leopold Ruppert

Individual Consultant for Renewable Energy and Energy Efficiency

IVORY COAST

Phone: -

E-mail: leopold.ruppert@gmail.com

Leopold Ruppert holds a Master Degree in mechanical engineering with specialization in renewable energy. Subsequent to his Master at the Vienna University of Technology, he did a PhD investigating the transient behaviour of diverse pumped storage plant schemes and their interaction with the power grid. Currently, he is working as Consultant based in Abidjan responsible for the technical evaluation of renewable energy projects across the dark continent.

\section{Robert Schmaranz}

KNG - Kärnten Netz GmbH

Arnulfplatz 2, A-9020 Klagenfurt/Wörthersee, AUSTRIA

Phone: +43 505251633 FAX: +4350 525951633

E-mail: robert.schmaranz@kaerntennetz.at

Robert Schmaranz graduated from Graz University of Technology with a master degree in electrical engineering in 2001. He received his Ph.D. in 2004 and his postdoctoral lecture qualification (habilitation) 2015. He is now responsible for the grid operation in the KNG-Kärnten Netz GmbH in Carinthia/Austria and is lecturer at Graz University of Technology covering the areas of energy systems and grid operation. His special interest lies in the topic of grid restoration.

\section{Christian Rupp}

KELAG - Kärntner Elektrizitäts-Aktiengesellschaft

Arnulfplatz 2, A-9020 Klagenfurt/Wörthersee, AUSTRIA

Phone: $+43(0) 463 / 525-5237$

E-mail: christian.rupp@kelag.at

Christian Rupp studied Electrical Engineering at Graz University of Technology and Financial and Industrial Management at Graz Karl-Franzens University. Since 2005 he has been working for KELAG. He is head of the department generation and technical services.

\section{Christian Tengg}

KELAG - Kärntner Elektrizitäts-Aktiengesellschaft

Arnulfplatz 2, A-9020 Klagenfurt/Wörthersee, AUSTRIA

Phone: +43(0)463 5255200

E-mail: christian.tengg@kelag.at

Christian Tengg received his master's degree in electrical engineering in 2008 from Graz University of Technology, Austria. From 2008 to 2015 he held various positions at KNG-Kärnten Netz GmbH. In 2015 he transferred to KELAG where he is currently head of operation and maintenance of Hydro Power Plants in Austria. 